\title{
ANCLAJE, DESEO Y ESTULTICIA: UN ANÁLISIS A TRES MENSAJES PUBLICITARIOS
}

\author{
Anchorage, desire and foolishness: Analysis of three advertising messages
}

Pablo Bonilla Elizondo*

\section{RESUMEN}

Este artículo tiene el propósito de reflexionar sobre las formas de deseo que inciden en el sujeto contemporáneo y la configuración de su bioética. Para ello, se parte del análisis de tres mensajes publicitarios, enfocándose en las estrategias retóricas que articulan texto e imagen bajo procesos de anclaje y que nos permiten analizar otras formas del mismo proceso que operan a nivel ideológico. Se espera también, oponer al anclaje propio de mensaje publicitario, el relevo infinito de los signos como fundamento para el desarrollo de una inquietud de sí.

Palabras clave: Semiótica, anclaje, sociedad de consumo, mensajes, bioética, inquietud de sí.

\begin{abstract}
This paper aims to reflect upon the forms of desire which affect the contemporary subject and shape their bioethics. For this purpose, the analysis will start with three pieces of advertisement, focusing on the rhetorical strategies that link text and image under anchorage processes that allow us to analyze other forms of the same process operating at the ideological level. Also it intended to contrast the anchorage of the advertising, to the infinite relief of signs as foundation for the development of a care of the self.

Key Words: Semiotics, anchorage, consumer society, advertising, bioethics, care of the self.
\end{abstract}

Universidad de Costa Rica, Profesor, Escuela de Filología, Lingüística y Literatura. Costa Rica

Correo electrónico: pablobonillaucr@gmail.com

Recepción: 4/07/14 Aceptación: 22/05/15. 


\section{El automóvil del pueblo}

"En el fondo no hay más que una dura y feroz novedad: ustedes no están en el lugar donde sucede su destino. Ustedes no tienen destino. Ustedes no tienen y no son. A cambio de la realidad, se les ha dado una apariencia perfecta, una vida bien imitada."

Franco Fortini (Rancière, 2013: 35-36)

Un simple y moderado anuncio gráfico, publicado por Volkswagen en Estados Unidos en la década de los 60 para promover su Escarabajo 1200, ha tomado notoriedad en el mundo académico después de formar parte de la lectura de cinco mensajes publicitarios realizada por Umberto Eco en la Sección B de su libro La Estructura Ausente (Eco, 2005: 265-267) dedicada a los mensajes visuales. La lectura crítica de Eco a este anuncio gráfico, sin lugar a dudas redimensiona esa simpleza y moderación bajo una intencionalidad que evidencia la habilidad argumentativa de la imagen, y además reincide sobre la tipología redundante del mensaje publicitario que a pesar de su destreza no deja de ser "enfático" (Barthes, 1992: 30).

Tal crítica ha hecho progresar dicha imagen del ámbito publicitario al ámbito didáctico, eso sí en direcciones distintas, dos de ellas claramente opuestas. La primera como un análisis aislado, orientado a visualizar estrategias de comunicación para la promoción de productos que van más allá de los lugares comunes y que buscan un público más "audaz". En ese sentido, los publicistas y sus maestros han convertido esta imagen en un referente de como cierta destreza retórica (o pensar fuera del canasto) puede allanar contextos complicados para la comercialización de un bien de consumo'.

La segunda la valora como parte de un análisis integral de las diversas formas de articulación discursiva, donde el mensaje publicitario debe confrontarse con las estrategias comunicativas de diversas producciones simbólicas como el arte, la arquitectura y la política. En este segundo orden, la imagen señala el interés que ha despertado en el último siglo la sociedad de consumo y sus estrategias retóricas, en tanto formas que determinan un entramado de relaciones complejas entre la identidad, el lenguaje, lo social y las estructuras de poder político y económico.

Es el propósito de este artículo retomar tal imagen para trascender el ingenio publicitario, y orientar una crítica de las formas de deseo contemporáneo que rigen y determinan las identidades y las dinámicas sociales. Para ello, añadiremos al corpus otros fragmentos comerciales que nos permitan iluminar algunas contradicciones inherentes del mensaje publicitario, del cual se espera emanen otras contradicciones de orden político que resulten a su vez provechosas para repensar al sujeto contemporáneo y, por otro lado, cómo incide la propaganda en la constitución de su bioética ${ }^{2}$.

\section{Escarabajo 1200}

Umberto Eco, en el análisis a este mensaje publicitario, se centra en la relación retórica que establece el registro visual con el escrito. Para Roland Barthes (1992) el texto que confluye con una imagen cumple mayoritariamente dos funciones sobre ella: de relevo, ampliando la pluralidad misma de las imágenes y estableciendo un juego de expansión sémica; y de anclaje, reduciendo la pluralidad de la imagen y los peligros propios de la incertidumbre. La función de anclaje, típica en la retórica publicitaria, debe asegurar la efectividad del mensaje y evitar cualquier grieta que haga deslizar algún análisis sobre sus códigos y menos de sus propósitos. En la imagen del Escarabajo 1200, el registro escrito cumple la función de anclaje, evidenciando lo que la imagen sugiere: la modestia del automóvil (este se encuentra ubicado en la parte superior de la lámina y en una proporción reducida con respecto al espacio blanco que lo rodea).

Pero, como bien lo afirma Eco, la modestia se presenta como un epítrope, una figura retórica que concede al adversario lo que este objetaría desde el inicio. Lo que provoca que la publicidad aparente una sinceridad, transparencia y franqueza inusual: un diálogo frontal con el posible comprador suponiendo cierta complicidad, suponiéndolo como un igual y argumentando cosas que este ya sabe. Por supuesto, que esto 
se opone a las estrategias más comunes de la publicidad, que en la medida de lo posible evade exponerse como tal, estableciendo una comunicación sesgada para manipular e influir en la construcción de deseos a partir de las supuestas necesidades de sus lectores.

El registro verbal del anuncio en cuestión es el siguiente:

\section{«NO SE ALARMEN POR SU BAJO PRECIO»}

“1.625 dólares. Este es el precio del nuevo Volkswagen. Pero mucha gente no quiere comprarlo. Creen que merecen algo más caro. Este es el precio que pagamos por el precio que pedimos. Otros tienen miedo a comprarlo: no comprenden cómo podemos vender un coche a buen precio sin hacer un coche barato. He aquí por qué: como nuestra fábrica no cambia la forma del coche cada año, no hemos de cambiar cada año la fábrica. Lo que no nos gastamos en la apariencia, nos lo gastamos en mejorar las posibilidades de adquisición. La producción en masa reduce los costos. Y los VW han sido producidos en un número (más de diez millones hasta hoy) superior al de cualquier otro coche en la historia. Nuestro sistema de refrigeración por aire en el motor posterior reduce los costos porque elimina el radiador, bomba de agua y transmisión. No hay gadgets fantásticos accionados por pulsadores (los únicos pulsadores están en las puertas, y aún estos los ha de accionar usted. Cuando usted compra un VW tiene lo que paga. Lo que no le damos son las baratijas. Y usted no ha de pagar por lo que no le damos" (Eco, 2005: 265-266).

Pero la epítrope, percibida en este anuncio gráfico, cumple una función que va más allá de la simple construcción de confianza. El texto, en su extensión, hace evidente su ser publicidad, vemos al mensaje luchando contra el código a la hora de afirmase como publicidad e inmediatamente atacar a la publicidad misma. Este acto reflexivo, que podemos relacionar con una de las estructuras dobles visualizadas por Roman Jakobson (1984), agrieta el sistema publicitario en tanto introduce una cualidad rara e inusual en él: la sinceridad. Si bien es cierto, desde el ámbito de los estudios publicitarios, este tipo de contrapublicidad ${ }^{3}$, no es más que una estrategia audaz para un público audaz, que de cierta forma nunca pone en cuestión el sistema publicitario que lo alberga; desde cierta distancia histórica, el anuncio del Escarabajo 1200, proveniente de una Alemania en recuperación, inserta en la cultura estadounidense una crítica contundente a un sistema social que sobrepone los lujos por encima de la eficiencia, lo deseado por encima de lo necesitado.

Dado que lo necesario, en esencia, no debería requerir ser promovido, no queda la menor duda que la construcción del deseo es el propósito de la publicidad, y por ello, la publicidad en cuestión es increíblemente paradójica. Paradoja que podríamos extrapolar a nuestra contemporaneidad, en tanto pareciera que en el mundo de lo deseado, lo necesario requiere ser más publicitado. Hoy son extensivas las campañas publicitarias en torno a la protección del ambiente, en contra de la violencia doméstica, en contra del abuso infantil. La cantidad de dinero que podemos suponer que gastan hoy organizaciones no gubernamentales y gubernamentales en propaganda, con el afán de concienciar sobre lo necesario, hace evidente el juego desigual que desempeña lo necesario en el terreno del consumo.

\section{Tío Pelón}

Antes de vislumbrar otras conclusiones, pasemos ahora a otro ejemplo: en la parte trasera de un autobús, tapizada en toda su superficie, se lee el siguiente texto:

\section{"9 DE CADA 10 PREFIEREN TÍO PELÓN POR LO SUELTICO QUE QUEDA"}

El mensaje publicitario es sin duda bastante parco, ambiguo y extraño, más aún para quien no sepa que Tío Pelón es una marca de arroz en grano. Para los costarricense el mensaje, a pesar de su ambigüedad, es de lectura inmediata, no sólo porque se refiere a la marca mejor posicionada en el mercado de arroz, sino porque además se refiere a un estado del arroz 
cocido que dentro de la identidad costarricense es el adecuado; incluso se refiere a él como arroz "sueltico", no "sueltito" ni "suelto": para los Ticos ${ }^{4}$ esto es una afirmación de identidad y nacionalismo, un afirmación de una pertenencia nacional del producto (después veremos cómo esto se vuelve sobre el propio mensaje).

$\mathrm{Si}$ bien es cierto, la identidad nacional de la marca es una connotación que salta a la vista con facilidad, otra connotación dominante es la de cientificidad: el mensaje afirma una preferencia (de 9 de cada 10) a partir del método de la encuesta, propio de las ciencias sociales. No profundizaremos en los rigores que requiere una encuesta para poder obtener resultados fehacientes, no lo necesitamos para darnos cuenta, en una segunda lectura, que la veracidad y cientificidad de tal encuesta no existe, no sólo porque el mensaje no nos aporta los datos suficientes para constatar la información: cuándo se realizó, con qué instrumento, a cuántas personas se les aplicó, qué edades tenían, si eran mujeres, hombres, amas de casa, cocineros, etc., sino porque la cualidad motivo de preferencia no tiene que ver con la materia prima sino con la cocción. Resulta inverosímil que la industria que produce el arroz Tío Pelón haya diseñado genéticamente su grano para evitar que al cocinero común se exceda en el agua necesaria para que éste quede "sueltico". Lo que tenemos aquí, es una estrategia retórica que reposiciona la identidad costarricense, antes depositada en la cocción y ahora desplazada al grano, como si el grano de Tío Pelón fuera distinto (más costarricense) al resto de granos importados de China que en los últimos cinco años eliminaron casi por completo la producción nacional.

Además de afirmar la identidad costarricense en el clima de los arroces importados, el mensaje también pretende esconder la verdadera causa por la cual es el arroz preferido: el posicionamiento de marca. La cientificidad cumple la función de esconder la causa real de preferencia del arroz Tío Pelón dotando a los consumidores de otra razón, sin importar lo inverosímil que parezca. Ambas connotaciones, la identidad costarricense del producto y la "veracidad" de la consulta científica, se amalgaman para redirigir y evadir la realidad de producto. Una tercera lectura de mensaje, ya sea dada por la extrañeza inmediata o por el sometimiento del mensaje a una crítica (como el realizado en estos párrafos), revela la astucia publicitaria para redireccionar la atención del consumidor por medio de la evidente falta de sinceridad, manifestando al mismo tiempo lo que han querido ocultar: el posicionamiento de marca.

En relación con nuestro primer ejemplo, se marca una oposición clara a nivel de mensaje escrito, en el anuncio del arroz el texto es vago, ambiguo e impreciso, en el del bocho 1200 es enfático, extenso y preciso. La intención del primero es convertir la carencia en un valor (en eficiencia, en optimización de los recursos) con la intención de contradecir el sentido común y la ideología que lo sustenta. El segundo, al contrario, intenta perpetuar un sentido común que impone cierta ideología nacionalista. Sin embargo, en su visualidad ambos anuncios concuerdan en su sobriedad, dado que ambos, al final de cuentas se sustentan sobre cierto lugar común que los antecede y que hace posible toda publicidad: por más novedosa que sea, cierta base ideológica es necesaria para poder entregar mensajes eficientes en fragmentos discursivos tan efímeros como una página de prensa, una valla publicitaria o la parte trasera de un autobús.

Pareciera que para mantener la excitación por lo
novedoso, el lenguaje publicitario debiera entonces
sostener también la construcción estereotípica que
brinda el trasfondo de seguridad ante el riesgo por lo
desconocido. La marca se presenta como una síntesis,
un espacio simbólico y transaccional donde confluyen
desieos y aspiraciones de un mundo atribulado que
busca en el consumo un instante de solaz. A su vez, los
avisos representan la tranquilidad de un universo a la
medida del cliente (Suarez, 2012: 31).

Esta cuestión, a la larga, es fundamental para comprender que la lectura crítica de los mensajes publicitarios, al depender estos de una base ideológica, son capaces de revelarnos, en un movimiento de deconstrucción, cómo operan estas ideologías y que recubren. Es de mi criterio, por tanto, que la función primordial 
de la semiótica, como disciplina, debe alejarse de los tecnicismos y formalismos que la funcionalizan positivamente en la producción publicitaria, para acercarse a un método crítico que sea capaz de revisar las estructuras sociales en función de subvertir los mensajes dominantes, que la mayoría de las veces se vuelven opresores del ejercicio político propio de una democracia real. Como menciona Barthes en sus Elementos de Semiología (2009), la retórica es a los significantes, lo que la ideología es a los significados, y el análisis profundo de las estrategias retóricas nos permite desmenuzar los conglomerados de significados que se estereotipan y asumimos, desgraciadamente, como verdades inapelables, o peor aún, como motores inmanentes e inconscientes de nuestra bioética.

\section{Das Auto}

Cincuenta años después, Volkswagen, en el contexto del derroche espectacular del Superbowl anuncia su nuevo automóvil con un clip publicitario que agrada masivamente a toda una audiencia y desprende admiración de los entendidos ${ }^{5}$. El anuncio televisivo, carga dosis elevadas de identificación: lenguajes comunes sobre mitologías comunes; pero además, cierto carácter siniestro que devela una contradicción importante con su antecesor. Cincuenta años no son nada en la época donde todo tipo de relato es frágil.

Para aquellos, no muy familiarizados con la cultura estadounidense, el Superbowl es el nombre coloquial de la final nacional del "Futbol Americano". Más allá de esta contienda deportiva, que cada vez parece retroceder a un segundo plano, el evento se considera una fiesta nacional en los Estados Unidos (después del Día de Acción de Gracias, es el día de más consumo de licor y comida en el año). Este espectáculo televisivo es el más visto en ese país, propiciado en la última década por la creación de espacios en el intermedio para los no-amantes del futbol americano. Evidentemente la franja publicitaria es la más costosa, y cada año se intenta demarcar como un espacio de creatividad publicitaria, donde el costo de la franja debe ser compensado por un costo similar o mayor en producciones que incluyen grandes escenarios, efectos especiales y actores o figurantes famosos. Todo un derroche de retóricas comunes en la constitución de un semi-festival de anuncios televisivos. Así, en el medio-tiempo que descansa la acción deportiva, se da paso a conciertos de pop, rock y anuncios publicitarios "aptos para todo público".

En tal escenario, para promocionar su nuevo automóvil, Volkswagen nos presenta, bajo el nombre de The Force (Volkswagen, 2011), la ficción de un niño de entre seis o siete años con un traje completo de Darth Vader; es un traje que borra toda su identidad y lo redefine como el famoso general cibernético y maligno del Imperio Galáctico propio de la mitología de Stars Wars creada por George Lucas (1977); eso sí, en miniatura. Ese personaje, doblemente siniestro, secundado por la música propia de la saga, intenta dominar con telequinesis su propio universo: un hogar modelo del bienestar capitalista. Recorre la habitación de sus padres, la lavandería, el baño, el salón principal, el cuarto de su hermanita y la cocina, donde su madre le prepara un sándwich. En cada habitación fracasa en sus intentos telequinéticos de dominación, el perro Golden Retriever, los electrodomésticos y los peluches de su hermana ignoran la habilidad que George Lucas asignó a Darth Vader y que el niño ha retrotraído a su realidad. A la hora de degustar apático y decepcionado su emparedado llega su padre del trabajo, a simple vista un exitoso ejecutivo que conduce el último modelo Volkswagen. El niño en su último intento, ignora a su padre que desea abrazarlo e intenta una vez más con su telequinesis accionar el vehículo que se ha estacionado en el jardín; el auto para su sorpresa (retratada genialmente por su gestualidad) se enciende. El padre ha accionado la ignición desde la cocina con un mando a distancia, su esposa ríe indulgentemente. El logo de Mercedes aparece en la pantalla con el eslogan en alemán: Das Auto.

A primera vista, es una oda a la imaginación y al juego infantil: un niño que intenta reordenar su realidad y que enfrenta, 
gracias a la malicia del padre, la inverosímil posibilidad de realizarlo. Para el espectador -aquel que tiene la posibilidad de observar la ficción, de reconocer la fuente de la misma y la injerencia del padre que por un segundo transforma la ficción del niño en una posibilidad real (sólo para él)- el relato se le ha presentado íntegro, la habilidad gestual del niño (o mejor dicho del editor) y la dirección del corto han construido una narración fluida y sin distorsiones, los espectadores fácilmente confluyen. ¿Pero a qué se debe esto? ¿Será posible que una gestualidad y una narración bien articulada desde la dirección y edición sea suficiente para construir un relato íntegro en treinta segundos? Evidentemente no, ambos elementos deben depositarse sobre un marco ideológico con sus propias mitologías: un terreno común que es al mismo tiempo cimiento y obra. Si es deber producir algo apto para todo público, debe construir lo común y al público de lo común.

Ahora veamos el anuncio más de cerca y preguntémonos sobre ese marco ideológico: ¿sobre qué se construye su relato? Primero, la saga de Stars Wars, estrenada en 1977 y cuya primera trilogía termina en 1983 . Una segunda trilogía es estrenada en 1999 y concluida en el 2005 , pero precedida por retoques digitales a la primera trilogía que fueron suficiente novedad para relanzamientos constantes en salas de cine en la décadas de los noventas. Y una tercera trilogía en producción, anunciada con bombos y platillos después de que la corporación Disney comprara los derechos de la saga. Además, sobra mencionar la retrasmisión televisa de todas las películas, que desde la década de los ochentas no ha disminuido. Esto quiere decir que tal mitología ha estado presente en cada estadounidense (y en gran parte del resto de la civilización occidental) desde el abuelo que llevó a sus nietos en 1977 y hoy tiene noventa años, hasta el nieto que hoy tiene cuarenta y cinco años y lleva a sus propios nietos. Star Wars, sin lugar a dudas es el relato más común de la cultura occidental, rompiendo barreras generacionales y educativas que ningún otro relato ha podido romper. Crear otro relato más sobre él economiza una infinidad de tiempo, no es necesario, dentro de los treinta segundos del spot publicitario, explicar quién es Darth Vader.

Segundo, evidentemente el sintagma Darth Vader debe desplazarse paradigmáticamente a otro sintagma, al cual, por naturaleza no pertenece. Esto es indispensable, sino el anuncio no existe. Darth Vader se trasmuta al cuerpo de un niño que juega en un hogar promedio estadounidense. ¿Promedio? Sería muy ingenuo creer que todos los estadounidenses tienen ese poder de adquisición. Pero bueno, el mundo del deseo a menudo remplaza las realidades inmediatas de los espectadores. La verdad es que para la mayoría, el mundo del niño es tan imposible como la mitología Darth Vader; y sin embargo existe, es la sociedad del bienestar capitalista, sus productos, y sus personas distribuidas normativamente en los espacios de habitación, impolutos e incuestionables. El cuarto de la niña rosado, el perro Golden Retriever en el sillón de la sala (imposible un Pincher, ahora destinado a los bolsos de moda) el hombre llega del trabajo manejando su automóvil de lujo, su esposa, indulgente con sus bromas, solo pertenece a la cocina.

Hoy, con cierta tranquilidad observamos la publicidad "vintage" de los años sesenta, setenta e incluso ochenta, donde constantemente se denigraba a la mujer y se le determinaba, con violencia (incluso física) y en contraposición con el hombre, en el hogar. Anuncios gráficos que mostraban a una mujer siendo azotada por su marido por no probar el café antes de comprarlo, o de rodillas ante él, llevándole su desayuno a la cama, o siendo besada por su esposo con su delantal y con sus guantes de horno bajo el slogan: "so the harder a wife works, the cuter she looks"(Oddee, 2009). De alguna forma su pertenencia a otra época apacigua nuestra indignación al hacernos creer que hemos progresado: una ilusión retrospectiva nos inhibe a creer posibles estas representaciones en nuestra época. Sin embargo, este último anuncio superbólico nos hace meditar sobre si ese progreso es real o si simplemente las estrategias retóricas se han adaptado a formas "invisibles". Parece ser que los connotadores de 
la publicidad construyen para sí un propio velo que les posibilita sostener de forma subrepticia, en nuestra época, los mismos significados que nos indignan de épocas anteriores, sin tener ni una sola reacción.

El rol de la mujer debe indignar tanto como el rol del hombre, de la niña ausente y del propio Golden Retriever. En conjunto construyen "the american way of life", el reino del deseo se impone en torno a la adquisición de bienes y la escenificación de roles productivos. Incluso la imaginación del niño ha sido coartada a la adquisición de los productos Stars Wars. En comparación con la imaginación de Alicia, la del niño ya está dada, no debe reelaborar su físico, ni siquiera debe imaginar los poderes de Darth Vader, sólo debe comprar y usar el disfraz. La fantasía hoy ya no requiere ser imaginada sino comprada.

Por último, confrontemos este anuncio televisivo con el anuncio gráfico publicado 50 años atrás por la misma compañía para promocionar su Escarabajo 1200. A simple vista vemos una contradicción evidente entre el texto escrito del anuncio gráfico y su pequeña imagen, que niegan toda futilidad y ofrece con modestia solo lo necesario y, por otra parte, el anuncio televisivo que promociona un accesorio que posibilita encender el automóvil cuando su conductor esta fuera de él. A todas luces el colmo de los lujos innecesarios, ya que es absurdo prender el motor de un auto cuando no estás en él, dispuesto a manejarlo. Pero más allá de lógicas humorísticas, la oposición es fundamental en el rango de las connotaciones: el escarabajo 1200 vendía una utilidad dentro del marco de recuperación económica europea de posguerra, en donde la lógica de la productividad eficiencia y perdurabilidad para la reconstrucción dominaba el mercado por encima de los lujos. Hoy lo que vende Volkswagen en el medio tiempo del Superbowl, no es sólo un aditamento inútil, sino un modo de vida: el sueño americano, igual de inútil, inverosímil e imposible para la mayoría; retratado a través de sus propios estereotipos y roles, fundamentales para la construcción de un marco ideológico que regule y oriente los deseos, y todo tipo de fantasía, hacia el consumo.

\section{El anclaje y el relevo infinito de los signos}

Me atrevo a pensar el anclaje, progresando de la idea de una función que ejerce el texto escrito sobre la imagen o viceversa en circunstancias precisas de ciertos objetos semiológicos, como una relación compleja que construye, sostiene y proyecta un marco ideológico común donde se representan una serie de roles (el Superbowl, por ejemplo, como un teatro de los mismo). El anclaje es una lectura integra y completa, que hace confluir diferentes sustancias (más allá de lo visual y lo escrito) bajo un mismo significado repitente, con el propósito de orientar el deseo y evitar cualquier cuestionamiento a los objetos, sujetos, espacios y sus articulaciones.

La literatura y el arte, reino de lo plural y lo divergente: de los significantes que se relevan infinitamente para escapar de la clausura del significado, encuentra su remplazo en nuevos relatos de cultura mediática que cohesionan de forma eficaz la fantasía, los estereotipos y el deseo. Por ejemplo, en muchas ficciones, vemos el imaginario de Disney anclado no sólo a textos literarios recientes y ajenos a esta corporación mediática (por ejemplo los textos de Harry Potter), sino también, yace anclado a una configuración ideológica que fomenta un consumo contrario a una realidad material. En ese sentido la serie Fallen Princesses de Dina Golstein (2007-2009) hace un comentario pertinente al confrontar el ideal de los cuentos de hadas, filtrados por Disney, en contextos de conflicto social o político. En ella, podemos ver a Jazmín armada con una Ak47 en medio del conflicto bélico de Oriente Medio, o a Cenicienta tomando aguardiente en una taberna de obreros. Pero esta sencilla contraposición, puede ser cuestionada en tanto parece ofrecer una crítica eficaz dentro de lo esperado: sus significantes no retroceden mucho y no desestabilizan lo suficiente. Habrá que valorar el efecto vacuna en una sociedad donde la crítica social también es 
un objeto de consumo, un desdoblamiento dentro de lo simulado que permite cierta conciencia feliz por compartir una imagen o, en el mejor de los casos, aportar algunos dólares para que otros actúen. En ambos casos, nunca entra en cuestión el sujeto, nunca será objeto de su propia reflexión, al no encontrar fisuras críticas en su propia simulación. "Lo paradójico" ha sido ya presa de lo publicitario en un juego de anclaje con la propia doxa a la cual se oponía. En cierta medida obliga al pensamiento artístico, en la época de la viralidad, a subrayar una práctica de lo meta/para/dójico.

El infinito relevo de los signos, propuesto desde Charles Sanders Peirce en la forma del interpretante, debe ser asumido en arte como fundamento para el acto de reflexión y cuestionamiento constante bajo una inquietud de sí. En tanto, debe ser capaz de desestabilizar ciertos supuestos para una reflexión profunda que condense una nueva bioética más allá de cierta conciencia feliz del share o el like. Para ello debe buscar oponerse a las ficciones que lo suplantan, íntegras y totales, que además, completan el esquema de fantasía, estereotipo y consumo que caracterizan al estulto de hoy.

\section{Stultitia}

Michel Foucualt, en uno de sus últimos seminarios impartidos en el College de France (2011), teoriza ampliamente sobre la inquietud de sí o la epimeleia heautou derivada del gnothi seauton (conócete a ti mismo). La inquietud de sí conlleva una actividad crítica con respecto a sí mismo para: primero, el ejercicio futuro del buen gobierno (Alcibiades), y segundo, para una adecuada Instructio (Seneca), que no es una formación para el ejercicio profesional, sino como un tipo de blindaje integral que protege en contra de cualquier acontecimiento inesperado; al margen de cualquier especificación profesional, se trata de formarlo para que pueda soportar como corresponde todos los accidentes eventuales, todas las desdichas posibles, todas las desgracias y todas las caídas que puedan afectarlo (Foucault, 2011: 104). Principalmente la investigación realizada por Foucault evidencia que La epimeleia heatou conlleva una actividad crítica del sujeto con respecto a sí mismo, una herramienta o armadura para protegerse de la Stultitia. El stultos,

...es ante todo quien está expuesto a todos los vientos,
abierto al mundo externo, es decir, quien deja entrar
a su mente todas las representaciones que ese mundo
externo puede ofrecerle. Representaciones que acepta
sin examinarlas, sin saber analizar qué representan.
El stultus está abierto al mundo externo en la medida
en que deja que esas representaciones, en cierto
modo, se mezclen dentro de su propio espíritu -con
sus pasiones, sus deseos, sus ambiciones, sus hábitos
de pensamiento, sus ilusiones, etcétera-, de modo
que es, entonces, la persona que está expuesta a
todos los vientos de las representaciones externas
y luego, una vez que estas han entrado en su mente,
es incapaz de hacer la división, la discriminatio
entre el contenido de esas representaciones y los
elementos que nosotros llamaríamos, si ustedes
quieren, subjetivos, que se mezclan en ella. (...) Por
otra parte, y como consecuencia de ello, el stultus
es quien está disperso en el tiempo. El stultus es
quien no se acuerda de nada, quien no deja que su
vida pase, quien no trata de llevarla a una unidad
rememorando lo que merece recordarse, y (quien
lo dirige) su atención, su voluntad, hacia una meta
precisa y bien establecida. (Foucault, 2011: 135-136).

Pensar al stulto hoy, deberá re-identificarlo como un personaje determinante de la democracia contemporánea y su encadenamiento con la cultura de masas y las estrategias de manipulación mediática, que sin lugar a dudas sólo pueden ser efectivas ante quien esté expuesto a todos los vientos. Es por ello que es fundamental reafirmar la necesidad de promover una educación integral desde el seno de la educación pública, que más allá de una profesionalización, busque otorgar herramientas críticas para la vida. En ese contexto la semiótica debe ser pensada como herramienta crítica capaz de articular las complejidades identitarias, lingüísticas, políticas, sociales y artísticas de nuestro entorno mediático, para ofrecernos cierta claridad sobre lo que somos y cómo nos representamos. 
Notas

1. Sobre estas tendencias se recomienda la lectura del artículo: "La publicidad, el lenguaje del consumo. Redefinición y prospectiva" de Bernardo Suarez (2012).

2. Se utiliza este concepto bajo la caracterización realizada por Michel Foucault en la Hermenéutica del Sujeto (2001).

3. La contrapublicidad también se asocia con el subvertising, estrategía artística que subvierte la publicidad para construir un discurso crítico. No es uso que se le da a este concepto en este artículo.

4. Como normalmente se les conoce a los costarricenses, según la opinión común, esto se debe a cierto idiolecto que sustituye el diminutivo "ito" por "ico".

5. Fue la campaña de automóviles más exitosa del 2011Tracking de Publicidad del Automóvil de TNS. (Marketing Directo, 2012) y registró la mayor cantidad de visitas de un anuncio comercial en el dominio web Youtube.

\section{Bibliografía}

Barthes, Roland. (2000). Elementos de Semiología. En La aventura semiológica, 23-112. Barcelona: Paidós.

Barthes, Roland. (1992). Retórica de la imagen. En Lo obvio y lo obtuso. Imágenes, gestos, voces. Barcelona: Paidós Comunicación.

Eco, Umberto. (2005). La Estructura Ausente. Introducción a la Semiótica. Barcelona: Editorial Lumen.
Goldstein, Dina. (2007-2009). Fallen Princesses. Recuperado en http://dinagoldstein.com/ fallen-princesses

Jakobson, Roman. (1984). Ensayos de lingüistica General. Barcelona: Ariel.

Foucault, Michel. (2001). Hermenéutica del Sujeto. Buenos Aires: Fondo de Cultura Económica de Argentina.

Marketing Directo. (2012). La campaña "Darth Vader" de Volkswagen Passat, ganadora del premio BAIT 2012 de TNS. Recuperado en: http://www. marketingdirecto.com/actualidad/ publicidad/la-campana-darth-vader-devolkswagen-passat-ganadora-del-premiobait-2012-de-tns/\#PXm94xU2etssNqkJ

Oddee. (2009). 15 Sexist Vintage Ads. Recuperado en: http://www.oddee.com/ item_96674.aspx

Rancière, Jaques. (2013). Figuras de la Historia. Buenos Aires: Eterna Cadencia.

Suárez, Bernardo. (2012). La publicidad, el lenguaje del consumo. Redefinición y prospectiva. En Cuadernos del Centro de Estudios de Diseño y Comunicación, 12(39), 29-34.

Volkswagen. (2011). The Force. Recuperado e n : h t t ps://www.youtube.com/ watch? $\mathrm{v}=\mathrm{R} 55 \mathrm{e}-\mathrm{uHQna0}$

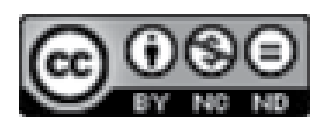

Este obra está bajo una licencia de Creative Commons

Reconocimiento-NoComercial-SinObraDerivada 4.0 Internacional. 
